\title{
Influence of Aluminum Coating Technology on Industrial Waste Management
}

\author{
${ }^{1}$ Lenar N. Shafigullin, ${ }^{2}$ Alsu A. Yusupova, ${ }^{3}$ Galina A. Medvedeva \\ ${ }^{1}$ Kazan Federal University \\ ${ }^{2}$ Kazan National Research Technological University \\ ${ }^{3}$ Kazan State University of Architecture and Engineering \\ Email:misharin_82@mail.ru,alsu16rus@yandex.ru,medvedevaga79@mail.ru
}

Received: 20 ${ }^{\text {th }}$ August 2019, Accepted: $30^{\text {th }}$ September 2019, Published: $31^{\text {st }}$ October 2019

\begin{abstract}
The work is devoted to the urgent issues of processing of sulfur-containing and ash-and-slag waste of industrial enterprises. The process flow scheme for obtaining of protective coatings on cement concrete, by impregnation in sulfur melt with high strength, performance properties, and resistance to aggressive environments, was developed. The technological parameters of the process were determined. The addition of ash and slag to the cement concrete allows not only to utilize the waste of heat power industry, but also to increase the strength of the material. Moreover, the applied technology of impregnation provides low thermal conductivity of concrete, and good thermalinsulation characteristics of the material. The increase in strength of samples, containing ash and slag waste, is due to the high dispersion and active surface of ash and slag. The influence of aluminum chloride, an electrophilic agent, on the properties of sulfur binder, was considered. It was shown, that the introduction of aluminum chloride contributed to a more effective protective coating, which provided the samples of cement concrete with high strength, density, and water resistance. The use of an electrophilic agent made it possible to intensify the process of obtaining of inorganic sulfides and composite materials, based on them. It was found, that the application of an electrophilic additive - aluminum chloride - significantly reduced the viscosity of sulfur melt, that was due to the formation of short-chain sulfur radicals. Such a sulfur melt has a fairly high penetrating ability, that provides the formation of a high-quality protective coating.
\end{abstract}

\section{Keywords}

Composite Materials, Sulfur, Ash and Slag Waste, Aluminum Chloride, Electrophilic Agent.

\section{Introduction}

An important area of scientific and technological development is the creation and implementation of new technologies and materials, which ensure the resource saving and meet the environmental requirements. In this regard, the problems of processing and utilization of industrial waste and by-products are of particular importance.

In the last decade, in Russia, it is observed the increase in production of industrial sulfur as a by-product in the processing and refining of oil, natural and flue gases [1]. Ash and slag wastes appeared as a result of the work of thermal power plants. They occupy large areas and are a source of pollution of air and water basins [2]. The issue of processing of sulfur-containing and ash-and-slag wastes of industrial enterprises remains unresolved.

Ash and slag mixtures are widely used as aggregates and fillers in concrete for various purposes [3-5]. This is determined by the grain and chemical composition, as well as the physical and mechanical characteristics.

The most promising is the use of sulfur as a binder, impregnating composition and as an additive in asphalt concrete. The use of sulfur as a raw material for the production of sulfides relates to the methods for improving the operational properties and increasing the products life.

It is known the methods of impregnation of wood, ceramic bricks, concrete structures in a sulfur melt. Sulfur impregnation is used for the products with a capillary-porous structure. However, in the literature there is no information about the impregnation of silicate materials in sulfuric melts, using various modifying reagents, as well as about the properties of the resulting coatings.

The theory of modification of cement-based materials with a sulfur melt suggests that the intensity of impregnation and the quality of products obtained are associated with the porous texture of three components of the structure: cement stone, aggregates, void defects between them. It should be noted, that the mechanisms, defining the impact of the structure on the properties of composites, obtained as a result of impregnation with a sulfur melt, are understudied up to the present [6].

Various modifying additives — sulfur stabilizers - are usually introduced into the composition of sulfur materials. The properties of the sulfur melt can be directionally controlled by changing the amount of modifying additives. As a result, after hardening, it is possible to obtain a material, characterized by a wide range of physical and mechanical properties $[7,8]$.

The transition of sulfur to the reactive form occurs as a result of the opening of cyclooctasulfur ring $\mathrm{S}_{8}$. The temperature and the presence of electrophilic, nucleophilic reagents and free radicals have a significant effect on the rate of this reaction. 
In our opinion, the use of electrophilic agent - aluminum chloride, would intensify the process of obtaining of inorganic sulfides and binders, based on them.

The aim of the work is to develop the technology for the production of protective coatings on cement concrete and concrete, based on ash and slag waste, using the method of impregnation in sulfur melt, modified with aluminum chloride, and to study the properties of the materials obtained.

\section{Methods}

The physical and chemical properties of the samples with coatings were tested according to:

GOST 7473-94 Concrete mixtures. Technical Specifications.

GOST 12730.1-78 Concretes. Methods of determination of density.

GOST 10180-90 (ST SEV 3978-83) Concretes. Methods for strength determination using reference specimens.

GOST 12730.3-78 Concretes. Method of determination of water absorption.

The resistance to aggressive media, especially to salt $(5 \% \mathrm{NaCl})$ and acid $(5 \% \mathrm{HCl})$ aggression was also investigated according to GOST 25881-83 Chemically resistant concretes. Methods of test.

Rheological tests were carried out using the device VUB-20, according to the method from GOST 32060-2013.

\section{Results and Discussion}

At the first stage, the samples of silicate concrete were investigated. The use of aluminum chlorine provided the activation of sulfur, contributing to the improvement of technological effectiveness of sulfur melt. Table 1 presents the test results of samples with a coating, obtained after impregnation in a sulfur melt with different contents of aluminum chloride - 1 and 5\% wt.

\begin{tabular}{|c|c|c|c|c|}
\hline Modifier & $\rho, \mathrm{g} / \mathrm{cm}^{3}$ & Water absorption, $\%$ & Compressive strength, MPa & Load, kgf \\
\hline Without impregnation & 1.93 & 15.03 & 4.79 & 182 \\
\hline Pure sulfur & 1.9512 & 12.28 & 8.18 & 311 \\
\hline $\mathrm{S}+1 \% \mathrm{AlCl}_{3}$ & 2.0287 & 10.46 & 9.06 & 275 \\
\hline $\mathrm{S}+2 \% \mathrm{AlCl}_{3}$ & 2.0731 & 8.76 & 14.76 & 560 \\
\hline $\mathrm{S}+3 \% \mathrm{AlCl}_{3}$ & 2.1578 & 7.83 & 18.5 & 703 \\
\hline $\mathrm{S}+7 \% \mathrm{AlCl}_{3}$ & 2.3964 & 6.23 & 18.66 & 710 \\
\hline
\end{tabular}

Table 1: Strength and Performance Properties of Cement Concrete Samples after Impregnation in a Sulfur Melt

Thus, the initial samples without a protective coating had the following characteristics: compressive strength - 8.2 $\mathrm{MPa}$, water absorption - $12.3 \%$, density $-1.9512 \mathrm{~g} / \mathrm{cm}^{3}$. After addition of aluminum chloride, the compressive strength of the samples increases. The values of this indicator are significantly increased with the introduction of 1$2 \%$ aluminum chloride into the sulfur melt. So, with the addition of more than $3 \%$ aluminum chloride, the compressive strength of the samples reaches $18 \mathrm{MPa}$.

The introduction of modifying additive provides the improvement of water-resistant properties of the materials, and contributes to uniform decrease in water absorption, with any amount of modifier. The samples of cement concrete with the coating, obtained by the impregnation in a modified sulfur melt, have the values of water absorption, meeting the requirements of GOST.

The addition of various modifiers to the sulfur melt improves the density of all samples. The introduction of modifying additive of aluminum chloride contributes to a uniform increase of density.

Thus, when electrophilic additive of aluminum chloride is introduced into the sulfur melt, the strength properties of coated materials increase by $20-100 \%$, and water absorption decreases by $2-3$ times.

The density of samples of concrete products with a protective coating, obtained by impregnation in sulfur melt, also increases, depending on the amount of modifying additives.

The samples with optimal composition were also tested for resistance to aggressive environments. The tests were carried out in 5\% solutions of hydrochloric acid and sodium chloride. As test indicators, the samples of uncoated cement concrete had a low resistance to these aggressive environments - 0.5 .

After soaking in a 5\% solution of hydrochloric acid, the samples without coating had a loose, fragile structure, with a large number of external defects (chips, cracks, etc.) (Figure 1). 


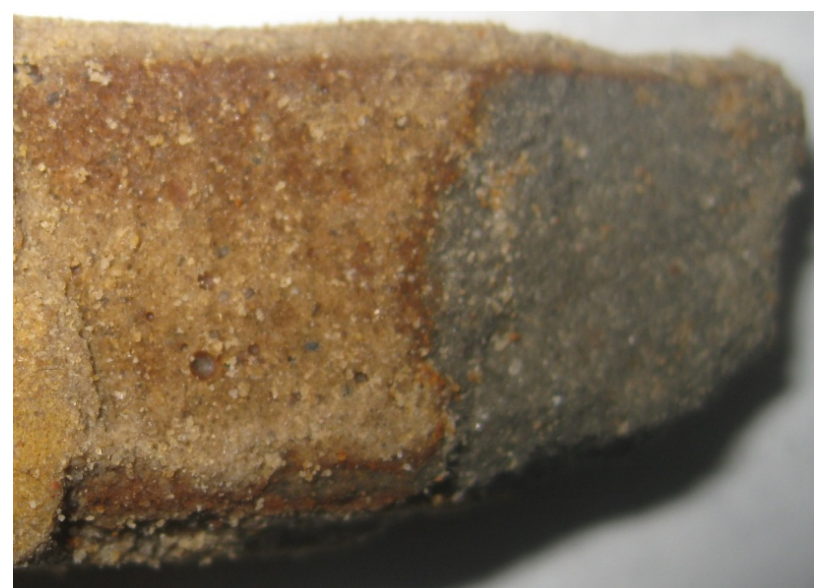

Figure 1: The Sample of Uncoated Silicate Concrete after Testing in a 5\% Solution of Hydrochloric Acid.

After testing in a solution of sodium chloride, the samples of cement concrete slightly changed their color, but the external defects were not revealed.

The samples with a protective coating, obtained as a result of application of modifying additive, had the coefficients of resistance to a solution of hydrochloric acid $-0.8-0.85$, to a solution of sodium chloride $-0.9-0.95$. The appearance of these samples after the test remained unchanged. Dense layer of a protective coating with a thickness of about $1 \mathrm{~mm}$ was clearly visible at the fracture in the cross section (Figure 2).

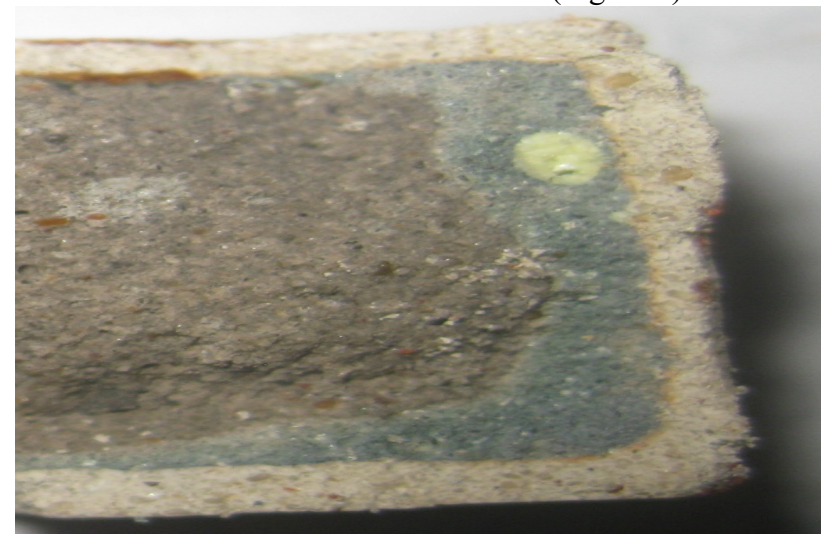

Figure 2: The Sample of Cement Concrete, Impregnated in a Sulfur Melt, Using a 3\% Aluminum Chloride Modifier, after Testing in a 5\% Solution of Hydrochloric Acid.

Further, the samples of cement concrete, with different content of ash and slag waste in the mixture $(33,66,100 \%$ wt) were obtained. They were impregnated in sulfur melt with different content of modifier. Then, manufactured samples were tested. The results of tests are presented in table 2.

\begin{tabular}{|c|c|c|c|c|c|}
\hline $\begin{array}{c}\text { Modifier, } \\
\text { weight \% }\end{array}$ & $\begin{array}{c}\text { Ash-slag, } \\
\text { weight } \%\end{array}$ & $\begin{array}{c}\text { Density } \\
\mathrm{g} / \mathrm{cm}^{3}\end{array}$ & $\begin{array}{c}\text { Compressive } \\
\text { strength, } \\
\mathrm{MPa}\end{array}$ & Water absorption $\%$ & $\begin{array}{c}\text { Thermal conductivity, } \\
\mathrm{W} / \mathrm{m}^{0} \mathrm{C}\end{array}$ \\
\hline $\mathrm{AlCl}_{3} 2 \%$ & 33 & 2.100 & 34.2 & 1.512 & 0.160 \\
\cline { 2 - 6 } & 66 & 1.821 & 33.3 & 0.853 & 0.139 \\
\hline $\begin{array}{c}\text { Without } \\
\text { impregnation }\end{array}$ & 66 & 1.492 & 7.2 & 4.123 & 0.151 \\
\hline
\end{tabular}

Table 2: Characteristics of Strength and Performance Properties of Optimal Cement Concrete Samples, Containing Ash and Slag Waste, and Impregnated in a Modified Sulfur Melt

The results of compressive strength test showed, that the strength of the cement concrete sample with high ash content decreased by 1.6 times, compared to the cement concrete sample without waste, that was caused by an increase in the porosity of the material. The strength of cement concretes, containing ash and slag, and impregnated in sulfur melt increased. The water absorption of the samples, impregnated in the modified sulfur melt, decreased by 5 times, compared with the non-impregnated samples, and amounted to $0.8 \%$. This meets the requirements of GOST. The indicators of resistance to aggressive environments also satisfied the requirements of regulatory documents. Thus, the impregnation of concrete with a modified sulfur melt, and the inclusion of ash and slag waste in the 
composition of cement concrete can improve the performance properties of the material. The increase in strength of samples, containing ash and slag waste, is due to the high dispersion and the active surface of ash and slag, that is determined by the composition of the waste (weight \%): $\mathrm{SiO}_{2}-47.7-52.2 ; \mathrm{Al}_{2} \mathrm{O}_{3}+\mathrm{TiO}_{2}-21.24-25.28 ; \mathrm{CaO}+\mathrm{MgO}$ $-4.3 ; \mathrm{Fe}_{2} \mathrm{O}_{3}-5.2-5.9$.

The changes in the viscosity of sulfur melt were determined, depending on the temperature and on the type of modifying additives, in order to define the impact of the studied modifying additives on the technological properties of the sulfur melt, and the properties of the resulting protective coatings.

The viscosity of sulfur melt is a key parameter of technological effectiveness of the process of cement concrete impregnation. It is obvious, that the melt, having a low viscosity, will have greater penetrating power and will provide a deeper protective layer with high protective properties.

The viscosity of sulfur with various modifying additives was determined using the device VUB-20. The research results are presented in Figure 3.

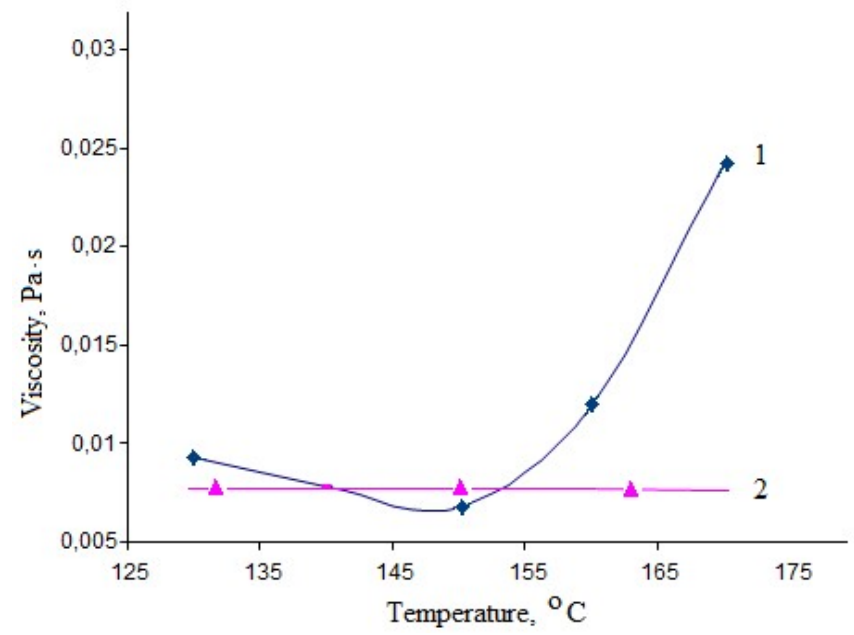

Figure 3: The Dependence of Viscosity on the Temperature of Pure Sulfur Melt (1) and Sulfur Melt with the Addition of Aluminum Chloride (2).

From the graph of dependence of the viscosity of sulfur melt with different contents of aluminum chloride on temperature, it is clear that with increasing temperature of the sulfur melt with modifiers, its viscosity increases in the temperature range from 150 to $170{ }^{\circ} \mathrm{C}$.

Sulfur melt is a thin liquid, the viscosity of which changes with the increase of temperature. When heated above $120{ }^{\circ} \mathrm{C}$, sulfur passes to a liquid state. At $159{ }^{\circ} \mathrm{C}$, it has the lowest viscosity, and eight-atom radicals are present in the melt. At $159.4{ }^{\circ} \mathrm{C}$, polymerization occurs, and short-chain radicals turn into long polymer chains. Viscosity sharply increases from $6.8 \mathrm{cps}\left(\right.$ at $150^{\circ} \mathrm{C}$ ) to $24.3 \mathrm{cps}\left(\right.$ at $170^{\circ} \mathrm{C}$ ). At a temperature $187^{\circ} \mathrm{C}$, the sulfur melt becomes dark brown and practically non-flowable. When heated above $187{ }^{\circ} \mathrm{C}$, the chains break, shorten, and the fluid becomes flowing again.

As can be seen from the graph of dependence of the sulfur melt viscosity, the addition of aluminum chloride in the sulfur melt reduces its viscosity. So, within the temperature range $130-150{ }^{\circ} \mathrm{C}$, the values of viscosity of pure and modified sulfur melt are similar. When heated above $160{ }^{\circ} \mathrm{C}$, the viscosity of pure sulfur melt rises sharply, and that of a modified melt decreases by three times. With the introduction of $2 \%$ aluminum chloride, the viscosity of sulfur melt remains low over the entire temperature range from 120 to $170{ }^{\circ} \mathrm{C}$. This can be explained by the formation of short-chain sulfur radicals in the melt. It is known, $[9,10]$ that when aluminum chloride is added, an electrophilic opening of the sulfur ring occurs, accompanied by a decrease in the binding energy between sulfur atoms and the formation of short-chain sulfur radicals (with 2, 4 and 6 sulfur atoms in the chain). Such a melt has the lowest viscosity.

Thus, aluminum chloride acts as electrophilic activator for the opening of sulfur ring, the formation of active shortchain radicals, thereby reducing the viscosity and surface tension of the melt, and increasing its penetrating ability.

On the other hand, being fixed on the terminal sulfur atoms, the radicals hinder the processes of polymerization, while maintaining the high technological properties of impregnating compositions. As a result, the wettability and penetration strength of the impregnating mixture improves, that contributes to the formation of a more reliable effective protective coating on cement concrete.

The initial cement concrete has a loose structure with pores and inclusions. After application of protective coating on silicate concrete, the uniform needle crystals, the size of which is much smaller than in the volume of free sulfur, are formed during the cooling of sulfur. With the addition of activator, the viscosity of sulfur melt decreases, forming the short reactive radicals, which can, firstly, more easily penetrate into the pore space, and secondly, facilitate further cross-linking of these radicals in the pores, and the formation of chemical bonds with the surface of cement concrete. 
Obtained coatings provide higher mechanical and performance properties of the materials (compressive strength 8.2 $\mathrm{MPa}$, water absorption $-12.3 \%$, density $-1.9512 \mathrm{~g} / \mathrm{cm}^{3}$ ) and protect against the aggressive environments.

Pore space also affects the performance properties. To increase the impregnating ability of the modified sulfur melt and to improve the output characteristics, it is necessary to structure the pore space optimally.

Thus, for the samples of cement concrete, impregnated with a modified sulfur melt, the strength properties increase by 3-4 times, water absorption decreases by 3 times, due to the better impregnation ability of the modified sulfur melt in the pore space.

Based on the obtained data, the concept scheme of the technology of application of the surface protective layer on the silicate concrete, by impregnation in a modified sulfur melt, is proposed. Such a technological scheme is most suitable for the stationary placement; for example, at the existing concrete product plant, as an additional technological section, where the part of products, manufactured by the plant, can be processed in sulfur melt. It is possible to use this method for a mobile installation, where the impregnation of products is carried out at a construction site immediately before their installation, for example, piles before their driving, or zero-cycle elements before their installation.

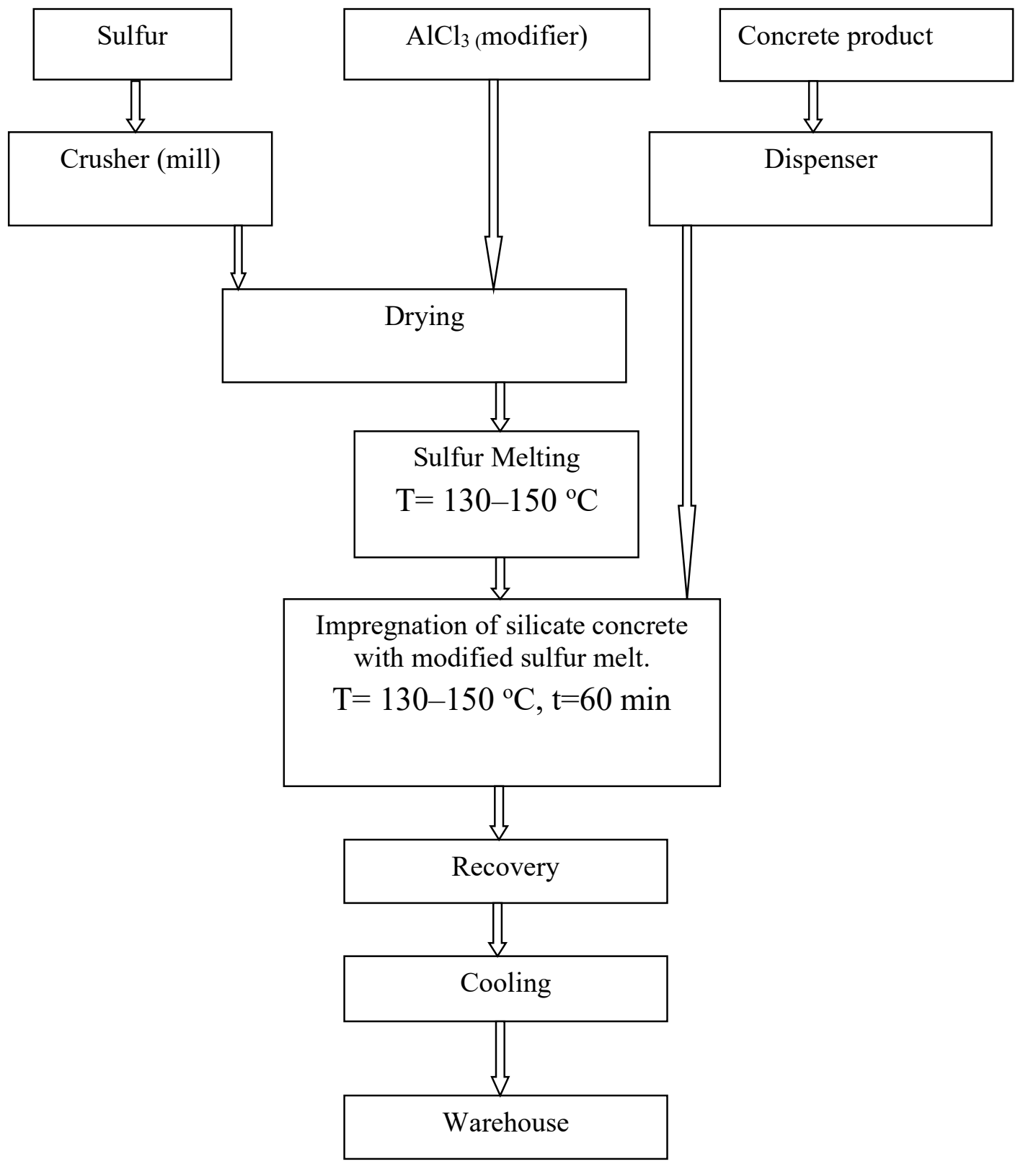

Figure 4: Schematic Diagram for Obtaining of Sulfide Coatings on Silicate Concretes, by Impregnation in a Modified Sulfur Melt. 
Much attention is paid as to the preparation of concrete, which must be drained before the impregnation, as to the preparation of sulfur melt.

Impregnation of concrete significantly improves its strength, density, reduces permeability to liquids and gases, increases frost resistance, weather resistance, and resistance to the aggressive environments. The low cost and availability of impregnating material contribute to the cheapening of the impregnation process.

The concept scheme of concrete processing in a sulfur melt (Fig. 4) includes heating of sulfur up to $140-150{ }^{\circ} \mathrm{C}$, drying and heating of concrete products to $120{ }^{\circ} \mathrm{C}$, immersing of products in a sulfur melt, their impregnation and cooling. The latter operation is important, because with rapid cooling, cracks and defects can form in the products.

Sulfur is passed through the crusher, and then is moved to the smelter, through a batcher, together with the suspended zinc chloride, at a temperature of $130-150{ }^{\circ} \mathrm{C}$. Finished silicate concrete is sent to the stage of impregnation in a modified sulfur melt at $130-150{ }^{\circ} \mathrm{C}$ for 1 hour (depending on the size of the concrete). The next step will be the extraction and gradual cooling of the product. Finished impregnated products are sent to the warehouse.

\section{Summary}

The technological scheme has been developed for the obtaining of protective coating on cement concrete, by impregnation in a sulfur melt, with high strength, performance properties and resistance to aggressive environments. The technological parameters of the process were determined.

It was shown, that the introduction of modifying additive of aluminum chlorides in the melt contributed to an increase in strength $(20-100 \%)$ and density of materials $(10-100 \%), 2-3$-fold reduction in water absorption and thermal conductivity, and improvement of resistance to aggressive media.

It was found, that the application of electrophilic additive (aluminum chloride) significantly reduced the viscosity of sulfur melt, that was associated with the formation of short-chain sulfur radicals. Such sulfur melt has a fairly high penetrating ability, that ensures the formation of a high-quality protective coating.

\section{Conclusions}

It is shown, that the introduction of aluminum chloride contributes to the obtaining of a more effective protective coating, which provides the samples of cement concrete with high strength, density, water resistance, and resistance to aggressive environments. The use of electrophilic agent allows to intensify the process of obtaining of inorganic sulfides and composite materials, based on them.

\section{Acknowledgements}

The work is performed according to the Russian Government Program of Competitive Growth of Kazan Federal University. This work was supported by the research grant of Kazan Federal University.

\section{References}

[1] Ismagilov, F.R. The ways of ecological optimization of sulfur production at gas and oil processing plants // Sulfur and sulfuric acid - 2017: Collection of materials of the 7th International Scientific and Practical Conference. M.: OAO GINTSVETMET Institute, 2017, Pp. 28-31.

[2] Putilin E.I., Tsvetkov V.S. The review of domestic and foreign experience in the application of wastes from the solid-fuel combustion at the thermal power plants. - M.: Soyuzdornii Publishing House, 2003. - 60 p.

[3] Alexandrova T., Korchevenkov S. Ecological and technological aspects of ash and slag wastes utilization, J. Ecol. Eng. 2017; 18(4):15-24.

[4] P.V. Menshova, Y.V. Khlupina, O.I. Nalesnika, A.V. Makarovskikha. Ash and Slag Waste as a Secondary Raw Material, Procedia Chemistry 10 (2014), pp. 184 - 191.

[5] Ivanov, I.A. Lightweight concretes with the use of ashes of power plants. - M.: Stroyizdat, 1986. - 136 p.

[6] Khasanov, R.R. Thin-walled products on cement basis, modified with sulfur: extended abstract of Cand. Sci. (Eng.) Dissertation / R.R. Khasanov. - Ufa, 2003. - 129 p.

[7] Korolev, E.V. Sulfur composite materials for radiation protection / E.V. Korolev, A.P. Proshin, V.I. Solomatov. Penza: PSUAC, 2001. - 208 p.

[8] Yusupova A. A., Akhmetova R. T., Treshchev A.A., Shafigullin L. N. Lakhno A.V., Bobrishev A.A. Sulfur Composite Technology from Oil Refinery Waste. International Journal of Applied Engineering Research, ISSN 0973-4562, vol. 11, No. 5 (2016), pp. 3057-3061.

[9] Yusupova A. A., Akhmetova R. T., Shafigullin L. N. Sulfur Composite Materials Based On Sulfide Containing Industrial Waste, Materials Engineering And Technologies For Production And Processing Iii Solid State Phenomena, Vol. 265, pp. 33-38, 2017.

[10] Abdel-Mohsen O. Mohamed, Maisa El Gamal. Sulfur based hazardous waste solidification, Environmental Geology 53(1):159-175 -2007). 